\section{The dilemma of diabetes: health care crisis in the Caribbean}

\author{
Henry S. Fraser ${ }^{1}$
}

1 University of the West Indies, Chronic Disease Research Centre, Bridgetown, Barbados; telephone: (246)-426-6416; fax: (246)-426-8406; e-mail: hfraser@uwichill.edu.bb
The epidemiologic transition in the Caribbean over the last 40 years has produced an epidemic of lifestyle-related chronic noncommunicable diseases. Among these are obesity, diabetes, and hypertension, along with such complications as stroke, heart disease, and amputations. The World Health Organization projects that the number of adults with diabetes in the Americas will double by 2025, and that most of the increase will occur in Latin America and the Caribbean (1). Both obesity and diabetes have been increasing in Barbados (2-4), in Trinidad $(5,6)$, and in Jamaica (7-9). Obesity (body mass index (BMI) $>30 \mathrm{~kg} / \mathrm{m}^{2}$ ) already occurs in $30 \%$ of Barbadian women $25-75$ years old, and overweight (BMI $>25 \mathrm{~kg} / \mathrm{m}^{2}$ ) in $57.8 \%$ of them (10). Diabetes occurs in $17 \%$ of Barbadians over age 40 (2). In Jamaica diabetes occurs in $17 \%$ of persons over age 25 , according to one study (7), and in $13.4 \%$, according to another study (8). The combination of a rapid increase in calorie intake and a decrease in physical activity, against a background of cultural traditions that favor female obesity (11), imposes an unmanageable burden on the limited health care resources of these small countries of the Caribbean.

Enormous research effort has been dedicated to evaluating diabetes care and outcome. There is clear evidence that good glycemic control reduces complications of type 1 diabetes (12), but the benefits of improving glycemic control in type 2 diabetes are modest, affecting mainly microvascular outcomes (retinopathy, nephropathy and neuropathy) (13). The United Kingdom Prospective Diabetes Study (UKPDS) has shown that control of hypertension is even more important than glycemic control in determining microvascular outcomes (14). On the other hand, macrovascular (cardiovascular and cerebrovascular) outcomes appear poorly related to glycemic control, and are more likely to be related to the multiple risk factors of obesity, hypertension, hyperlipidemia, and physical activity. Although there are many studies on glycemic control, there are few adequate studies of the benefits of multiple risk factor control, and guidelines for diabetes management are usually based on "expert" consensus rather than hard evidence.

A Pan American Health Organization (PAHO) workshop in St. Lucia in 1986 produced a review of the growing problem of diabetes in the Caribbean and guidelines for diabetes management (15). There was, however, no evaluation of the quality of care or control. In 1992 the Commonwealth Caribbean Medical Research Council (now the Caribbean Health Research Council) implemented a project to evaluate quality of care across the Caribbean and to develop updated, regional guidelines. The first report from that study (16) described the findings in Barbados, Trinidad, and Tortola (British Virgin Islands). In this issue of this journal Wilks et al. report the data from three clinics in Jamaica, the largest English-speaking Caribbean island, with a population of 2.6 million-and a struggling economy.

Neither of these two studies from the Caribbean is reassuring. Their findings are a major cause for concern, particularly with respect to the public clinics in Jamaica and Trinidad. Only two-thirds of the patients at the public clinic in Jamaica and a mere one-third of the patients in the Trinidadian public clinics had had blood glucose measured at least once in the preceding 12 months. Glycated hemoglobin measurements were not available in those 
countries' public clinics, and urine glucose was only recorded in $60 \%$ of patients in the Jamaican public clinic. In Jamaica poor blood glucose control occurred in virtually the same proportion in the public clinic (61\%) as in a specialty diabetes clinic $(62 \%)$, but the much higher use of insulin in the specialty clinic than in the public clinic ( $45 \%$ of patients using insulin versus $7 \%$ ) indicates that much more severe diabetics were being treated in the specialty clinic.

Treatment choices in the Jamaica public clinic were questionable: sulfonylurea in $88 \%$ of patients, with the addition of metformin in $41 \%$ of them but used alone only in one individual, in spite of the high prevalence of obesity, where it is recommended as the drug of first choice. The earlier article noted a similar low incidence of metformin use in Trinidad.

Control of hypertension was poor in all clinic settings in Jamaica, Barbados, and Trinidad. Blood pressure control was best in Tortola, where only $42 \%$ of public patients were uncontrolled. Tortola also showed the highest proportion of patients with a blood glucose recording, the most recent blood glucose recordings, and the lowest figures for poor blood glucose control. Tortola's consistently better control rates may be related to a PAHO program initiated five years earlier.

There were remarkable differences in the drugs chosen for hypertension treatment, perhaps partly related to cost. In the Jamaican report $75 \%$ of public patients received a low-cost, centrally acting drug (methyldopa or reserpine) and $23 \%$ of them received the moderately priced thiazide-reserpine combination drug Brinerdin (clopamide, reserpine, and dihydroergocristine), yet only $7 \%$ received a specific thiazide diuretic, which is available at very low cost. High-cost ACE inhibitors were most popular at the third institution surveyed in Jamaica, a private clinic. In the specialist diabetic clinic in Jamaica methyldopa and thiazide topped the list.

Finally, both the Jamaican report and the earlier report indicated that little counseling for nondrug or lifestyle management was recorded. While clinic records are often incomplete, the frequency of these aspects of care was usually in single figures, except in the Jamaican specialist diabetes clinic.

Following the studies in Barbados, Tortola, and Trinidad, new guidelines for diabetes management in the Caribbean were developed (17). After their distribution and minimal promotion, the guidelines' impact was evaluated in two studies $(18,19)$, which both found modest improvements in documentation of care and control.

Two questions must be asked. Firstly, can better glycemic and blood pressure control be achieved in the face of struggling economies and overburdened health care systems? Secondly, if glycemic control is difficult to achieve, should more effort be spent on other aspects of care?

While the large and costly UKPDS did not achieve ideal glycemic control, a number of studies from metropolitan centers have shown that it can be done. Miller et al. (20), managing endocrinology clinic diabetics with many comorbidities (and $57 \%$ on insulin), achieved average glycosylated hemoglobin ( $\mathrm{HbA1c}$ ) levels of $6.9 \%$, as well as levels of $8.0 \%$ or less in $89 \%$ of patients. The various clinic settings in these two papers on the Caribbean showed widely differing practices and widely different quality of control. This suggests that there is huge scope for rationalizing practices and prescribing, using evidencebased and low-cost treatments, such as diet and physical activity; metformin as a first-line drug for glycemic control; and low-dose thiazide as a first-line drug for hypertension control. Furthermore, the fact that minimal intervention showed modest gains suggests that comprehensive, multifaceted interventions could achieve much more. 
Secondly, there is a large body of evidence relating to the central role of lifestyle change with diabetes $(21)$, hypertension $(22,23)$, coronary heart disease $(24,25)$, and quality of life (26). Nevertheless, care of both diabetes and hypertension is driven by drug prescribing, and there is limited long-term data on the relative cost-effectiveness of nondrug treatments. At the point of health care delivery there needs to be political, professional, patient, and public commitment to radically altering the health care paradigm of the last 50 years, with its reliance on pills. Small Caribbean populations with high prevalences of diabetes and related lifestyle risk factors and comorbidities provide ideal "epidemiology laboratories" for scrupulously monitored interventions in care and in the health environment at relatively low cost. Such studies should take into account unique local problems and constraints, as has been suggested with the strategy of Essential National Health Research as espoused by the Council on Health Research for Development and by other groups. While these studies may not excite drug companies or cutting-edge laboratory scientists, they should be a top priority both for funding agencies and for health care providers, whose everincreasing expenditures should be informed by evidence of both efficacy and cost-effectiveness. The crisis in chronic disease care is already here for Caribbean, African-American, and other populations in rapidly "developing" countries, and the time for action is now.

\section{REFERENCES}

1. King H, Aubert RE, Herman WH. Global burden of diabetes, 1995-2025: prevalence, numerical estimates, and projections. Diabetes Care 1998;21(9):1414-1431.

2. Foster C, Rotimi C, Fraser H, Sundarum, Liao Y, Gibson E, et al. Hypertension, diabetes, and obesity in Barbados: findings from a recent population-based survey. Ethn Dis 1993;3(3):404-412.

3. Fraser H, Forrester T, Wilks R. The obesity epidemic of the Caribbean. West Ind Med J 1996;45(1):1-2.

4. Fraser H, Alert C. Obesity: its impact on health and the challenge for the future. London: Health in the Commonwealth; 1999.

5. Miller G, Kirkwood BP, Beckles GLA, Alexis SD, Carson DC, Byam N. Adult male allcause, cardiovascular and cerebrovascular mortality in relation to ethnic group, systolic blood pressure and blood glucose concentration in Trinidad, West Indies. Int J Epidemiol 1988;17(1):62-69.

6. Poon-King T, Henry MV, Rampersad F. Prevalence and natural history of diabetes in Trinidad. Lancet 1968;1:842-847.

7. Ragoobirsingh D, Lewis-Fuller E, Morrison EY. The Jamaican diabetes survey. A protocol for the Caribbean. Diabetes Care 1995;18(9):1277-1279.

8. Wilks R, Rotimi C, Bennett F, McFarlane-Anderson N, Kaufman JS, Anderson SGR, et al. Diabetes in the Caribbean: results of a population survey from Spanish Town, Jamaica. Diabet Med 1999;16(10):875-883.

9. Florey CDV, McDonald HJ, Miall WE. The prevalence of diabetes in a rural population of Jamaican adults. Int J Epidemiol 1972;1(2):157-166.

10. Rotimi CN, Cooper RS, Ataman SL, Osotimehin B, Kadiri S, Muna W, et al. Distribution of anthropometric variables and the prevalence of obesity in populations of West African origin: the International Collaborative Study on Hypertension in Blacks (ICSHIB). Obes Res 1995;3(Suppl 3):95s-105s.

11. Hoyos MD, Clarke H. Concepts of obesity in family practice. West Ind Med J 1987;36(2): 95-98.

12. The Diabetes Control and Complications Trial Research Group. The effect of intensive treatment of diabetes and progression of long-term complications in insulin-dependent diabetes mellitus. N Eng J Med 1993;329(14):977-986.

13. UK Prospective Diabetes Study (UKPDS) Group. Intensive blood-glucose control with sulphonylureas or insulin compared with conventional treatment and risk of complications in patients with type 2 diabetes (UKPDS 33). Lancet 1998;352(9131):837-853.

14. UK Prospective Diabetes Study Group. Tight blood pressure control and risk of macrovascular and microvascular complications in type 2 diabetes. UKPDS 38. BMJ 1998;317(7160): 703-711. 
15. Pan American Health Organization. The control of diabetes mellitus in the Caribbean. Bridgetown, Barbados: PAHO; 1988.

16. Gulliford MC, Alert CV, Mahabir D, Aryanayagam-Baksh SM, Fraser HS, Picou DI. Diabetes care in middle-income countries: a Caribbean case study. Diabet Med 1996;13(6):574-581.

17. Commonwealth Caribbean Medical Research Council. Managing diabetes in primary care. Port of Spain, Trinidad: CCMRC; 1996.

18. Alert CV, Fraser HS. Diabetes mellitus in Barbados: an assessment of the CCMRC/Ministry of Health's effort to improve management in the public sector. West Ind Med J 1997;46(suppl 2):20.

19. Gulliford MC, Mahabir D. A five-year evaluation of intervention in diabetes care in Trinidad and Tobago. Diabet Med 1999;16(11):939-945.

20. Miller CD, Phillips LS, Tate MK, Porwoll JM, Rossman SD, Cronmiller N, et al. Meeting American Diabetes Association guidelines in endocrinologist practice. Diabetes Care 2000;23(4):444-448.

21. Ryan AS. Insulin resistance with aging: effects of diet and exercise. Sports Med 2000;30(5):327-346.

22. The Trials of Hypertension Prevention Collaborative Group. The effects of nonpharmacologic interventions on blood pressure of persons with high normal levels. JAMA 1992;267(9):1214-1220

23. Moore TJ, Vollmer WM, Appel LJ, Sacks FM, Svetkey LP, Vogt TM, et al. Effect of dietary patterns on ambulatory blood pressure: results from the Dietary Approaches to Stop Hypertension (DASH) trial. Hypertension 1999;34(3):472-477.

24. Puska P, Nissinen A, Tuomilehto J, Salonen JT, Koskela K, McAlister A, et al. The community-based strategy to prevent coronary heart disease: conclusions from the ten years of the North Karelia Project. Ann Rev Public Health 1985;6:147-193.

25. Winkleby MA, Taylor CB, Jatulis D, Fortmann SP. The long-term effects of a cardiovascular disease prevention trial: the Stanford Five-City Project. Am J Public Health 1996;86(12):1773-1779.

26. Plaisted CS, Lin PH, Ard JD, McClure ML, Svetkey LP. The effects of dietary patterns on quality of life: a substudy of the Dietary Approaches to Stop Hypertension trial. J Am Diet Assoc 1999;99(8 Suppl):S84-89. 